\title{
How much do people know about male sexual problems? A survey in a selected population sample
}

\author{
Edoardo S. Pescatori ${ }^{1}$, Anna Baldini ${ }^{2}$, Fabio Parazzini ${ }^{3,}{ }^{4}$, Nicola Ghidini ${ }^{5}$, Giovanni L. Briganti ${ }^{2}$ \\ ${ }^{1}$ Andrology Service, Hesperia Hospital, Modena, Italy; \\ ${ }^{2}$ Cittadinanzattiva, Bologna, Italy; \\ ${ }^{3}$ Dipartimento di Scienze Cliniche e di Comunità, Università degli Studi di Milano, Italy; \\ ${ }^{4}$ Fondazione IRCCS Ca' Granda Ospedale Maggiore Policlinico, Milano, Italy; \\ ${ }^{5}$ Urology Department, Hesperia Hospital, Modena, Italy.
}

\begin{abstract}
Summary Objectives: Our purpose has been to investigate by an ad hoc questionnaire the knowledge of several aspects of male sexual dysfunction in a significant sample of men and women (largely not physicians) attending an International Health Care Exhibition, held in Italy.

Materials and methods: The survey took place during Exposanità, 2018 edition, aimed at medical and non-medical professionals. We devised as investigation tool an ad hoc anonymous questionnaire in two versions, one for each sex. Object of this report are questions addressing subject's knowledge of prevalence of erectile dysfunction (ED), ED causes, ED as early sign of coronary heart disease/myocardial infarction, available ED treatments and attitudes towards penile prosthesis, and reimbursement of ED treatments. Results: As many as 1094 Convention attendees (495 men, 599 women) participated to the survey (about $4 \%$ of total attendees). Mean sample age was 40.5 years in men and 39.9 years in women. Forty-three percent of the sample worked in healthrelated professions, $5.9 \%$ being physicians. Respondents globally over-estimated the prevalence of ED. Both responding men
\end{abstract} and women rated psychologic and lifestyle factors as the most frequent ED causes. The majority of responders did not regard ED as a possible predictor of cardiovascular events. Oral pills resulted the most known ED treatment by both men (77.2\%) and women (79.1\%). Psychotherapy ranked as the second most known treatment approach. Other effective ED treatments (intracavernosal injections, vacuum erection device, penile prostheses) were known by a minority of men (22.2-27.9\%) and women (19.2-20.2\%). Roughly half of the sample (50.7\% of men and $48.4 \%$ of women) were willing to choose (men) or to support (women) the penile prosthesis option in cases of severe ED; majority of both sexes (71.3\% of men and $76.3 \%$ of women) expressed no resistances to the perspective of penile prosthesis use. Vast majority of men (80.3\%) and women (80.4\%) considered that coverage for ED treatments should be provided by the National Health System.

Conclusions: The outcomes of our survey show both an elevated prevalence of misconceptions on the role of organic factors in the etiology of ED, and ignorance of the implications of ED on cardiovascular health. Knowledge of available second level ED treatments resulted scanty. Nonetheless, when confronted with the most aggressive treatment, penile prosthesis, majority of both genders responders would undergo/support this surgery, should it be the only way to solve the erectile problem. In this perspective, population appears ready and overall keen to a treatment option that too often is not addressed by majori- ty of the medical community when counseling men with severe $\mathrm{ED}$ not responsive to conservative approaches.

KEY WORDS: Erectile dysfunction; Awareness; Penile prosthesis; Risk factors; Impotence.

Submitted 18 May 2019; Accepted 21 May 2019

\section{INTRODUCTION}

Male sexual dysfunctions have been significantly acknowledged by the medical community in recent years only: elucidation of male sexual pathophysiology and availability of effective treatments date no more than 3 decades $(1,2)$. Even more recent is the acquisition that erectile dysfunction (ED) can allow early diagnosis, or be a predictor/sentinel event for future cardiovascular events [i.e. ischemic heart disease (IHD), myocardial infarction (MI)] and dysmetabolic conditions (i.e. diabetes) $(3,4)$. These concepts are well acknowledged by specialists (Andrologists, dedicated Urologists/Endocrinologists), but seldom by the rest of the medical community. The general population appreciates even less all the above, and too often men with sexual problems bypass medical consultations for improper embarrassment, turning to Internet for both online information and self-medication. Some detrimental consequences of such scenario include: overlooking underlying specific risk factors and/or medical conditions that are consequently not identified and not addressed, and lack of exposure to some second and third line effective treatments (i.e. intracavernosal vasoactive drugs and penile prostheses). The purpose of this survey has been to investigate by an "ad hoc" questionnaire the knowledge of several aspects of male sexual dysfunctions in a significant sample of men and women (largely non physicians) attending an International Health Care Exhibition, held in Italy.

Members of two regional associations for people rights tightly cooperated for the realization of this project: Cittadinanzattiva - Bologna section (www.cittadinanzattivaer.it) (AB, ESP, GLB) and ASSERTIVO (Associazione per la SaluteSEssuale e RiprodutTIVa dell'uOmo) (ESP, NG). 


\section{MATERIALS AND METHOdS}

\section{Setting}

The International Health Care Exhibition where the survey took place was Exposanità (www.exposanita.it), held in Bologna (Italy) from 18 to 21 April, 2018. Exposanità is the second largest European International Health Care Exhibition in terms of number of exhibitors and product range; it is held in Bologna every two years since 1982. It is dedicated to health care and assistance, and it is aimed at all medical and non-medical professionals who operate in various ways in the public and private sectors.

The total number of visitors attending the 2018 edition has been 30199 .

\section{Survey tool: the questionnaire}

An ad hoc anonymous questionnaire has been created (ESP, FP) for the purpose of this survey; the questionnaire had two versions, one for each sex.

It consisted of a preliminary section with three questions on age, occupation, relational status, and a question for men only if they ever suffered of uro-andrologic conditions.

This tool was preliminarly evaluated by experts for its content, and a limited number of questionnaries was administered to non-experts to ascertain questions comprehension. A formal validation was not deemed appropiate as this questionnaire simply investigates the level of knowledge of specific areas.

The ensuing 11 core questions addressed the following areas:

- subject's knowledge on frequency, causes, consequences and treatment modalities/reimbursement for ED; attitudes toward penile prosthesis surgery in case of severe ED. These areas will constitute the focus of this report; the respective questions (male version) are reported in Appendix (see Supplementary Materials).

- knowledge of frequency of premature ejaculation, risks linked to penile trauma during intercourse, attitudes towards sexual/reproductive screening for female versus male children. Such areas will be addressed in future reports.

\section{Questionnaire administration}

Cittadinanzattiva volunteers handed out the questionnaire to men and women attending Exposanità during the first three days of the event; the questionnaire was self-administered. Participants were asked to fold the completed questionnaires and place them in dedicated boxes, located in several spots in the convention area.

\section{Data analysis}

Mean (standard deviation, SD), median (range) or frequency (percent, \%) were computed as appropriate. When appropriate confidence limits at 95\% of the proportions were computed. Differences in proportions were tested using the chi-square test.

\section{RESULTS}

Out of 30199 Exposanità attendees 1094 (495 men and 599 women) filled the questionnaire.
Table 1.

Characteristics of study participants according to gender.

\begin{tabular}{|c|c|c|c|}
\hline & $\begin{array}{l}\text { Women } \\
\text { №. }(\%)^{*}\end{array}$ & $\begin{array}{c}\text { Men } \\
\text { №. (\%) }\end{array}$ & $\begin{array}{l}\text { Chi square } \\
\text { value }\end{array}$ \\
\hline \multicolumn{4}{|l|}{ Age (years) } \\
\hline Mean (SD) & $39.9(13.4)$ & $40.5(15.4)$ & \\
\hline$<30$ & $184(30.7)$ & $154(3.1)$ & \\
\hline $30-<45$ & $185(30.9)$ & $156(31.5)$ & \\
\hline $45-<65$ & 207 (34.6) & $143(28.9)$ & \\
\hline 65 or more & $23(3.8)$ & $42(8.5)$ & \\
\hline \multicolumn{4}{|l|}{ Occupation } \\
\hline Medical doctor & $25(4.2)$ & $40(8.1)$ & \\
\hline Nurse & $98(16.4)$ & $47(9.5)$ & \\
\hline Other health professions & $135(22.5)$ & $110(22.2)$ & \\
\hline Other non health professions ${ }^{\circ}$ & $333(55,6)$ & $294(59,4)$ & $1.37(p=n s)^{00}$ \\
\hline Missing & $8(1.3)$ & $4(0.8)$ & \\
\hline \multicolumn{4}{|c|}{ Married/common-low wife/husband } \\
\hline Yes & $372(62.1)$ & $257(51.9)$ & \\
\hline No & $215(35.9)$ & $224(45.3)$ & $0.80 ; p<0.01$ \\
\hline Missing & $12(2.0)$ & $14(2.8)$ & \\
\hline \multicolumn{4}{|l|}{ History of uro andrologic diseases } \\
\hline Yes & --- & $120(24.2)$ & \\
\hline No & ---- & $367(74.1)$ & \\
\hline Missing & -- & $7(1.4)$ & \\
\hline \multicolumn{4}{|c|}{$\begin{array}{l}\text { *The sum does not add up the total due to missing values. } \\
\text { - Including retired subjects. } \\
\text { oo Health vs non health professions. } \\
S D=\text { Standard deviation. }\end{array}$} \\
\hline
\end{tabular}

Table 1 details the characteristics of study participants according to gender. Mean sample age was 40.5 years (15.4 SD) in men and 39.9 years (13.4 SD) in women. Forty-three percent of the sample worked in health-related professions without a significant difference between men and women; physicians represented $5.9 \%$ of the sample.

A stable couple relation was present in $51.9 \%$ of men and $62.1 \%$ of women.

A history of uro-andrologic diseases was reported by $24 \%$ of men.

Table 2 shows the answer to questions about knowledge towards ED: $28.1 \%$ of men estimated a prevalence of ED in the general population $<10 \%$, and $16.3 \%$ responders $>40 \%$. The corresponding figures in women were $24.7 \%$ and $22.5 \%$ (Chi square heterogeneity $\mathrm{p}=14.19, \mathrm{p}<$ 0.05).

Both responding men and women rated psychologic and lifestyle factors as the most frequent causes of ED.

The subset of responders that most acknowledged organic conditions and radical pelvic surgery as frequent ED causes is represented by health care professionals.

The majority of responders of both sexes and all ages did not regard ED as a possible predictor of IHD. The subset of responders that most acknowledged ED as a predictor of such condition is represented by health care professionals (data not shown in table).

Oral pills are the most known ED treatment by both men (77.2\%) and women (79.1\%).

Psychotherapy is the second most known treatment approach for both sexes: $38.4 \%$ in men, and $41.9 \%$ in women, respectively. 
Table 2.

Knowledge/awareness about erectile dysfunction (ED).

\begin{tabular}{|c|c|c|c|c|c|c|}
\hline & $\begin{array}{l}\text { Women } \\
\text { №. }(\%)^{*}\end{array}$ & $\begin{array}{c}\text { Men } \\
\text { №. (\%) }\end{array}$ & $\begin{array}{l}\text { Chi square } \\
\text { value }\end{array}$ & $\begin{array}{l}\text { Health } \\
\text { professions }\end{array}$ & $\begin{array}{l}\text { Non health } \\
\text { professions }\end{array}$ & $\begin{array}{l}\text { Chi square } \\
\text { value }\end{array}$ \\
\hline \multicolumn{7}{|l|}{ How often do you think ED is common? } \\
\hline 3 out of 100 men & $40(6.7)$ & $46(9.3)$ & & $38(8.4)$ & $47(7.5)$ & \\
\hline 10 out of 100 men & $108(18.0)$ & $93(18.8)$ & & $77(16.9)$ & $47(7.5)$ & \\
\hline 20 out of 100 men & $132(22.0)$ & $148(29.9)$ & & $113(24.8)$ & $163(26.0)$ & \\
\hline 30 out of 100 men & $158(26.4)$ & $122(24.6)$ & & $128(28.1)$ & $163(26.0)$ & \\
\hline 40 out of $100 \mathrm{men}$ & $97(16.2)$ & $58(11.7)$ & & $68(14.9)$ & $86(13.7)$ & \\
\hline 50 out of 100 men & $38(6.3)$ & $23(4.6)$ & $14.19, p<0.05$ & $21(4.6)$ & $(39(6.2)$ & \\
\hline \multicolumn{7}{|l|}{ Which do you think are the most frequent causes of ED?** } \\
\hline Psycological conditions & $333(67.3)$ & $475(79.3)$ & $\begin{array}{c}20.30 \\
p<0.01\end{array}$ & $316(69.5)$ & $482(76.9)$ & $\begin{array}{c}7.51 \\
p<0.05\end{array}$ \\
\hline Hypertension & $121(24.4)$ & $117(19.5)$ & $\begin{array}{c}3.84 \\
p=0.05\end{array}$ & $108(23.7)$ & $129(20.6)$ & $\begin{array}{l}1.54 \\
\text { POns }\end{array}$ \\
\hline Diabetes & $107(21.6)$ & $111(18.5)$ & $\begin{array}{l}1.61 \\
p=n s\end{array}$ & $119(26.2)$ & $99(15.8)$ & $\begin{array}{c}17.60 \\
p<0.01\end{array}$ \\
\hline Vascular diseases & $180(36.4)$ & $182(30.4)$ & $\begin{array}{c}4.37 \\
p=0.04\end{array}$ & $167(36.7)$ & $193(30.8)$ & $\begin{array}{c}4.16 \\
p<0.05\end{array}$ \\
\hline Unhealthy lifestyles & $279(56.4)$ & $373(62.3)$ & $\begin{array}{c}3.93 \\
p=0.05\end{array}$ & $259(56.9)$ & $388(61.9)$ & $\begin{array}{c}2.70 \\
p<n s\end{array}$ \\
\hline Infectious diseases & $63(12.7)$ & $45(7.5)$ & $\begin{array}{c}8.28 \\
p<0.01\end{array}$ & $59(13.0)$ & $48(7.7)$ & $\begin{array}{c}8.35 \\
p<0.05\end{array}$ \\
\hline Radical pelvic surgery for prostate / bladder cancer & $171(34.5)$ & $210(35.1)$ & $\begin{array}{l}0.03 \\
p=n s\end{array}$ & $179(39.3)$ & $196(31.3)$ & $\begin{array}{c}7.60 \\
p<0.05\end{array}$ \\
\hline Old age & $258(52.1)$ & $274(45.7)$ & $\begin{array}{c}4.41 \\
p=0.04\end{array}$ & $211(46.4)$ & $315(50.29$ & $\begin{array}{c}1.58 \\
p=n s\end{array}$ \\
\hline Trauma of the penis & $109(22.0)$ & $157(26.2)$ & $\begin{array}{l}2.58, \\
\mathrm{p} \mathrm{ns}\end{array}$ & $131(28.8)$ & 135821.5) & $\begin{array}{c}7.50 \\
p<0.05\end{array}$ \\
\hline \multicolumn{7}{|c|}{ Do you think that the presence of ED can be an "alarm bell" for subsequent development of which of the following diseases?** } \\
\hline Obesity & $110(18.4)$ & $123(24.8)$ & $\begin{array}{c}6.79 \\
p=0.01\end{array}$ & $112(24.6)$ & $\begin{array}{c}118(18.8) \\
p=0.02\end{array}$ & 5.29 \\
\hline Kidney diseases & $80(13.4)$ & $53(10.7)$ & $\begin{array}{c}0.18 \\
p=n s\end{array}$ & $59(13.0)$ & $72(11.5)$ & $\begin{array}{c}0.55 \\
p=n s\end{array}$ \\
\hline Myocardial infarction/coronary hearth diseases & $191(31.9)$ & $177(35.8)$ & $\begin{array}{c}0.18 \\
p=n s\end{array}$ & $172(37.8)$ & $193(30.8)$ & $\begin{array}{c}5.81 \\
P<0.05\end{array}$ \\
\hline None & $270(45.1)$ & $196(39.6)$ & $\begin{array}{l}0.07 \\
p=n s\end{array}$ & $173(38.0)$ & $289(46.1)$ & $\begin{array}{c}7.02 \\
p<0.05\end{array}$ \\
\hline \multicolumn{7}{|l|}{ What treatments for ED do you know?** } \\
\hline Supplements & $67(11.2)$ & $69(13.9)$ & $\begin{array}{c}0.21 \\
p=n s\end{array}$ & $64(14.1)$ & $70(11.2)$ & $\begin{array}{c}2.74 \\
p=n s\end{array}$ \\
\hline Psychotherapy & $251(41.9)$ & $190(38.4)$ & $\begin{array}{c}0.24 \\
p=n s\end{array}$ & $196(43.1)$ & $244(38.9)$ & $\begin{array}{c}1.89 \\
p=n s\end{array}$ \\
\hline Oral drugs & $474(79.1)$ & $382(77.2)$ & $\begin{array}{c}0.43 \\
p=n s\end{array}$ & $356(78.2)$ & $491(78.3)$ & $\begin{array}{c}0.00 \\
p=n s\end{array}$ \\
\hline Intracavernosal injections & $115(19.2)$ & $110(22.2)$ & $\begin{array}{c}0.22 \\
p=n s\end{array}$ & $119(26.2)$ & $105(16.7)$ & $\begin{array}{c}14.21 \\
p<0.05\end{array}$ \\
\hline Vacuum erection devices & $134(22.4)$ & $137(27.7)$ & $\begin{array}{c}0.04 \\
p=n s\end{array}$ & $148(32.5)$ & $122(19.5)$ & $\begin{array}{c}24.05 \\
p<0.01\end{array}$ \\
\hline Penile prosthesis & $121(20.2)$ & $138(27.9)$ & $\begin{array}{c}0.00 \\
p=n s\end{array}$ & $143(31.4)$ & $112(17.9)$ & $\begin{array}{c}26.97 \\
p<0.01\end{array}$ \\
\hline
\end{tabular}

The other listed effective ED treatments (intracavernosal injections, VED, penile prostheses) are known by a minority of men (22.2-27.9\%) and women (19.220.2\%).

Dietary supplements are referred as possible ED treatment by $13.9 \%$ of men and by $11.2 \%$ of women.

No significant differences in terms of answers emerged among different age ranges and different occupations.

Two questions addressed the perspective of treatment of severe ED by penile prostheses (Table 3).

The first explored the willingness to choose (men) or to support (women) the penile prosthesis option: roughly half of the sample (50.7\% of men and $48.4 \%$ of women) was in favor of this choice.

The second question investigated possible resistances to the use of penile prostheses, leaving the possibility of a free comment on the reason/s for such resistances. Majority of both sexes expressed no resistances (71.3\% of men and $76.3 \%$ of women).

The main reason for resistance was concerns related to the surgical procedure.

The majority of both responding men (80.3\%) and women $(80.4 \%)$ considered that coverage for ED treatment should be provided by the National Health System. 
Table 3.

Attitude towards the use of penile prosthesis.

\begin{tabular}{|c|c|c|c|}
\hline & $\begin{array}{l}\text { Women } \\
\text { №. (\%) }\end{array}$ & $\begin{array}{c}\text { Men } \\
\text { No. (\%) }\end{array}$ & $\begin{array}{l}\text { Chi square } \\
\text { value }\end{array}$ \\
\hline \multicolumn{4}{|c|}{$\begin{array}{l}\text { If you or your partner had an ED not responding to drugs, what would you } \\
\text { choose/recommend? }\end{array}$} \\
\hline Live with the problem & $249(41.6)$ & $222(44.8)$ & \\
\hline $\begin{array}{l}\text { I would like to solve the problem } \\
\text { with penile prosthesis }\end{array}$ & $290(48.4)$ & $251(50.7)$ & $0.06 ; p=0.81$ \\
\hline Missing & $60(10.0)$ & $22(4.1)$ & \\
\hline \multicolumn{4}{|c|}{ Would you have any concern about the use of prosthesis? } \\
\hline None & $457(76.3)$ & $353(71.3)$ & \\
\hline Yes & $142(23.7)$ & $142(28.7)$ & $3.50 ; p=0.06$ \\
\hline \multicolumn{4}{|c|}{$\begin{array}{l}\text { Do you think that the costs related to the treatment of ED should be paid } \\
\text { by the national health service? }\end{array}$} \\
\hline Yes & $481(80.3)$ & $398(80.4)$ & \\
\hline No & $85(14.2)$ & $84(17.0)$ & $0.00 ; p=n s$ \\
\hline Missing & $33(5.5)$ & $13(2.6)$ & \\
\hline
\end{tabular}

\section{Discussion}

Male sexual dysfunctions represent a medical area that has been, and is, heavily investigated in many perspectives: dysfunctions prevalence, specific risk factors, impact of distinct dysfunctions on quality of life, treatment modalities and related patient/partner satisfaction and compliance, etc. A recurrent issue among caregivers is the limited access of sufferers to appropriate treatment options, and how to overcome it. Surprisingly, minimal attention has been given by the scientific community on what lay people know of male sexual dysfunctions: specific scientific reports are scanty, at best $(5,6)$. This is a potential significant bias when planning effective strategies to promote male sexual health and better access to effective treatments, as we feel it should be known upfront what people know and what do not know, what people expect, fear, wish, in order to devise targeted interventions. The purpose of our study has been to explore the knowledge of some key aspects of male sexual dysfunctions in a selected population sample expected to have a knowledge of andrologic problems not inferior to the average general population, being professionals working in the health care area, a very minor part only represented by physicians (less than 6\%). In order to do so we devised a questionnaire structured in an epidemiologic perspective. A questionnaire investigating the simple knowledge does not require a formal validation, but an expert evaluation and the administration of a few questionnaires to assess the comprehensibility of the questions. This phase was conducted prior to the investigation by the working group. On the other hand, to interview for example the same group of subjects after a period of time with the same questionnaire is biased by the fact that it is possible that many respondents tend to gather information on the topic of the survey after the first administration of the questionnaire.

Following, we analyze the outcomes of our survey. Respondents globally over-estimated the prevalence of $\mathrm{ED}$, in fact about $70 \%$ of responders declared that the frequency of ED is $20 \%$ or more. Published studies refer to an overall ED prevalence in Italy of $10 \%(7,8)$. One possible reason for this finding is that sexuality issues draw the attention of lay public, to the extent that they can be perceived more prevalent than their reality.

When requested their opinion on the most frequent ED causes, responders incorrectly selected psychological issues, while as many as $80 \%$ of them did not regard diabetes and hypertension as leading ED causes. It is of no surprise that the correct answers of organic conditions and radical pelvic surgery have been more frequently selected by health care professionals. Similarly, the majority of responders of both sexes and all ages did not regard ED as a possible predictor of IHD; other Authors reported similar findings $(9,10)$. The subset of responders that most acknowledged ED as a predictor of such condition was again represented by health care professionals.

Oral pills are the most known ED treatment by both men (77.2\%) and women (79.1\%). Psychotherapy is the second most known treatment approach for both sexes: $38.4 \%$ of men, and $41.9 \%$ of women, respectively.

The other listed effective ED treatments (intracavernosal injections, VED, penile prostheses) are known by a minority of men (22.2-27.9\%) and women (19.2-20.2\%) only.

Interestingly, the penile prosthesis option as treatment for severe ED is conceptually accepted by half of the sample of both men and women, we can assume largely not directly/indirectly involved in this condition. Furthermore, a sharp majority of the sample would not foresee any problem/resistance in having intercourse by means of the penile prosthesis; of the minority that would have concerns with the prosthesis option the main emerging reason is some sort of fear related to the surgical procedure. Such outcomes clash with the attitude of the medical community not dedicated to penile surgery that too often negatively depicts the prosthesis option, despite its key role in treating severe ED cases as those resulting from radical prostatectomy, diabetes, Peyronie's disease (11).

Vast majority of our sample, both men and women, considered that coverage for ED treatment should be provided by the National Health System. This suggests that ED is considered as a significant condition that deserves treatment, and that therapies for ED are not perceived as lifestyle issues.

\section{Study limitations and strengths}

We upfront elected to investigate a selected sample of professionals, and accordingly we do not aim to extend our findings to the general Italian population. A potential limitation of the study is that the interviewed subjects were randomly identified among exhibition participants, but it is possible that subjects who were present all the period of Exposanità were more likely interviewed. In any case the distribution of participants was largely similar with the participants to the convention. Finally, the participation rate was very high and the missing value very few. The strengths of the study included the fact that it provides information from a large series of men and women, accounting for about 4\% of all Exposanità attendees. Despite the study design limitations, the results of this large survey give a general picture of the opinion about ED in the Italian population. 


\section{Conclusions}

Our investigation provides for the first time in Italy a view on what a large sample of men and women think of male sexual dysfunctions and related treatments. The population we investigated was represented by professionals involved in the health care area; it can be easily assumed that their knowledge of the questioned topics is at least not inferior of that of the general population. The outcomes of our survey show that also in this more-thanaverage knowledgeable sample there are misconceptions both on the prevalence of organic factors in the etiology of erectile dysfunction and on the implications of ED on IHD. Such findings underscore the need of educational programs aimed to promote population awareness on the real ED risk factors, and their tight correlation with cardiovascular conditions: it is expected that ultimately informed men can adopt healthy lifestyles that could promote both sexual and cardiovascular health.

When enquiring the knowledge of available treatments for ED it emerged a scanty awareness of second level treatments. Nonetheless, when confronted also with the most aggressive treatment, i.e. penile prosthesis, majority of both genders responders would elect to undergo/support this surgery, should it be the only way to solve the erectile problem. In this perspective population appears ready and overall keen to a treatment option that too often is not addressed by the majority of the medical community when counseling men with severe erectile dysfunctions not responsive to conservative treatments.

\section{AUthORS' CONTRIBUTIONS}

Edoardo S. Pescatori: study ideation and study design, manuscript writing; Anna Baldini: study design, study conduction, manuscript reviewing; Fabio Parazzini: study design, statistical analysis, manuscript reviewing Nicola Ghidini: study conduction; Giovanni L. Briganti: study conduction

\section{ACKNOWLEDGEMENTS}

Authors would like to thank Stefano Piazza (President), and Mauro Angiolini (Secretary) of the Association ASSERTIVO
(ASsociazione per la Salute SEssuale e RiprodutTIVa dell'uOmo), for condivision of the study, support and strategic advices.

\section{REFERENCES}

1. Kim N, Vardi Y, Padma-Nathan H, et al. Oxygen tension regulates the nitric oxide pathway. Physiological role in penile erection. J Clin Invest 1993; 91:437-42.

2. Virag R. About pharmacologically induced prolonged erection. Lancet. 1985; 1:519-20.

3. Jackson G. Prevention of cardiovascular disease by the early identification of erectile dysfunction. Int J Impot Res. 2008; 20 Suppl 2:59-14.

4. Carrillo-Larco RM, Luza-Dueñas AC, Urdániga-Hung M, et al. Diagnosis of erectile dysfunction can be used to improve screening for Type 2 diabetes mellitus. Diabet Med. 2018; 35:1538-1543.

5. Laumann EO, Nicolosi A, Glasser DB, et al. Sexual problems among women and men aged 40-80 y: prevalence and correlates identified in the Global Study of Sexual Attitudes and Behaviors. Int J Impot Res. 2005; 17:39-57.

6. Low WY, Wong YL, Zulkifli SN, Tan HM. Malaysian cultural differences in knowledge, attitudes and practices related to erectile dysfunction: focus group discussions. Int J Impot Res. 2002; 14:440-5.

7. Parazzini F, Menchini Fabris F, Bortolotti A, et al. Frequency and determinants of erectile dysfunction in Italy. Eur Urol. 2000; 37:43-9.

8. Bortolotti A, Parazzini F, Colli E, Landoni M. The epidemiology of erectile dysfunction and its risk factors. Int J Androl. 1997; 20: 323-34.

9. Shabsigh R, Kaufman J, Magee M, et al. Lack of awareness of erectile dysfunction in many men with risk factors for erectile dysfunction. BMC Urol. 2010 5; 10:18.

10. Kałka D, Domagała Z, Rakowska A, et al. Modifiable risk factors for erectile dysfunction: an assessment of the awareness of such factors in patients suffering from ischaemic heart disease. Int J Impot Res. 2016;28:14-9.

11. Pescatori E, Alei G, Antonini G, et al. INSIST-ED: Italian Society of Andrology registry on penile prosthesis surgery. First data analysis. Arch Ital Urol Androl. 2016; 88:122-7.

\section{Correspondence}

Edoardo S. Pescatori, MD (Corresponding Author)

info@andrologiapescatori.it

Andrology Service, Hesperia Hospital

Via Arquà 80/B - 41100 Modena (Italy)

Anna Baldini, Mrs

a.baldini@cittadinanzattiva-er.it

Giovanni L. Briganti (medical student)

giovanni.briganti1990@gmail.com

Cittadinanzattiva

via Castiglione, 24 - 40124 Bologna (Italy)

Fabio Parazzini, MD

fabio.parazzini@unimi.it

Dipartimento di Scienze Cliniche e di Comunità, Università degli Studi di Milano

Via Commenda 9/12 - 20122 Milano (Italy)

Nicola Ghidini, MD

info@nicolaghidini.it

Urology Department, Hesperia Hospital

Via Arquà 80/B - 41100 Modena (Italy) 